gradually became organized. In a short time, fluid formed on the treated side, the patient complained of dyspnea, and examination revealed fluid on the untreated side, the level being at the nipple line. One quart of a serous exudate was removed, with relief of symptoms and no return of the fluid formation. This patient has been under observation four years, under pneumothorax treatment two years of that time, and today the case is well arrested, no pneumothorax treatment having been given for two years.

\title{
COMMENT
}

It is interesting to note that in each case the one aspiration was sufficient, and that there was no further accumulation of fluid on the untreated side. The cases differ from Fishberg's, however, in that there was no absorption of the fluid on the treated side.

Another interesting feature in each of our cases is the fact that, with the available breathing space very much restricted, the patients showed no signs of cyanosis. It is true that the first patient was extremely dyspneic at all times until relieved by aspiration, but the second was fairly comfortable, except on exertion.

We can see no reason for discontinuing the pneumothorax treatment as noted by Fishberg. In both patients the refills were kept up, in one for only a few months, owing to his death from other complications, and in the other for nearly a year after the formation of fluid on the untreated side.

\section{A NEW APPROACH TO THE SEMILUNAR CARTILAGES}

Percy Willard Rogerts, M.D., New York

Believing that the period of convalescence following operation for excision of the semilunar cartilages of the knee could be shortened by early mobilization of the joint, I have, dur-

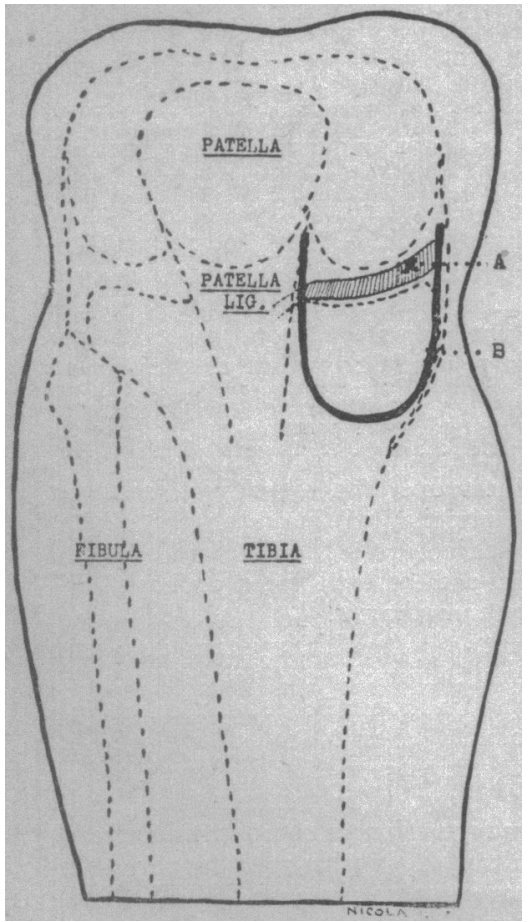

Fig. 1.-Line of incision for excision of internal semilunar cartilage; $A$, internal semilunar cartilage; $B$, line of incision. ing the last two years, been using an approach which eliminates strain on the wound when the knee is flexed and obviates the necessity of suturing the synovial membrane. All but one of the eight patients thus far operated on at the Hospital for Ruptured and Crippled have been able to walk without crutches and to sit with the knee flexed to a right angle on the sixth day, and to resume their usual activities, with practically full joint function, at the end of two weeks.

In all joint cases in which the part is immobilized for a considerable time after operation, psychology is a factor in retarding recovery. There is always present the fear of injuring the joint when it is moved; and especially is this true if motion is at all painful. To prevent this, it has been my custom to explain to the patient before operation what the aftertreatment will be. He is told that motion within the limit of pain will stimulate the circulation and prevent swelling, thus shortening his stay in the hospital, and that he will be expected to move the joint as soon as he comes out of the anesthesia and to repeat this every two hours. Passive motion is prohibited. Strange to say, there is practically no discomfort accompanying this early mobilization and much less swelling than when the knee is splinted. It is; therefore, easy to maintain the patients' cooperation, and occasionally it is necessary to restrain them in their ambition to increase the arc of flexion too rapidly.

The purpose of this approach is to so place the wound that no strain will come on it when the knee is bent. This is accomplished by using a blunt $\mathrm{V}$-shaped incision, one a um

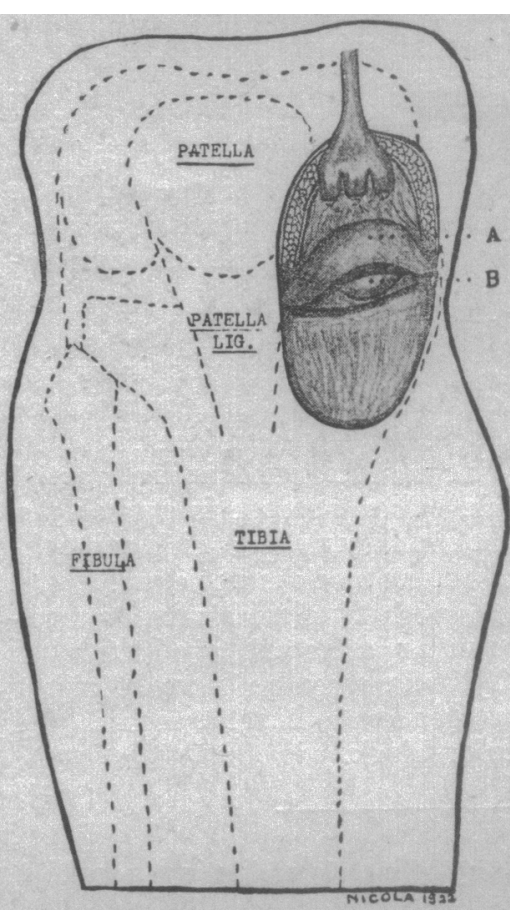

Fig. 2.-Flap retracted upward, showing exposure of meniscus on its under surface; $A$, internal semilu
$B$, medial condyle of femur. of which starts about three eighths of an inch above the upper border of the tibial condyle, and follows down the border of the patellar ligament for an inch and $a$ half. The knife is then carried transversely for a short distance, and then upward, inside of the lateral ligament to the level of the upper end of the opposite arm, as shown in Figure 1. All tissues overlying the tibia, including the periosteum, are cut at the same time. A sharp periosteal elevator is used to raise the V-shaped flap, which is retracted upward until the coronary ligament is exposed. This is incised transversely at its attachment to the tibia. As retraction is continued, the lower surface of the meniscus will appear on the under sur-

face of the flap, as shown in Figure 2. The cartilage is now grasped by forceps and, with a narrow-bladed knife, is dissected out. The wound is closed by several interrupted chromic gut sutures approximating the margins of the periosteum and other fibrous structures. Pulling down the flap closes the transverse opening in the synovial membrane, and no sutures are required. The skin is closed with silk. The firm suturing of the periosteum and adjacent structures prevents any strain on the skin wound even when the knee is flexed to 90 degrees, and there is, therefore, no interference with repair. Should stitch infection occur, as happened in one of my cases, the wound is so far removed from the joint that there is no occasion for anxiety. In this particular case, the patient was discharged with practically normal function at the end of two weeks.

Removal of a meniscus by this method requires a little more time than by more direct incisions, but the difference is so slight it is not worth consideration in view of the rapid convalescence which ensues.

576 Fifth Avenue.

\section{HEMORRHAGIC DISEASE OF THE NEW-BORN WITH DIRECT} TRANSFUSION INTO LONGITUDINAL SINUS THROUGH ANTERIOR FONTANEL

\section{John A. Shoemaker, M.D., Berea, Ohio}

Mrs. L. S., aged 32, a normal secundipara, was delivered normally of an 8 pound girl, Aug. 21, 1922, after three hours' labor in the hospital. The baby's life was entirely uneventful until August 24, when, at 3:30 p. m., the attending physician was called to the hospital with the urgent message that the baby had vomited an immense quantity of blood, which had soaked through the mother's gown and into the bedding. The baby had nursed a few minutes previously, and was about to be returned to the nursery. From $3: 30$ to $4: 30$ 